\title{
Textos Multimodales para el fortalecimiento de la Inteligencia Emocional ${ }^{1}$
}

\section{Multimodal texts for the strengthening of Emotional Intelligence.}

DOI: http://dx.doi.org/10.17981/cultedusoc.9.2.2018.07

Fecha de recepción: 27/06/2018. Fecha de aceptación: 21/09/2018

Kenia Pava ${ }^{2}$ iD

Alvaro Acuña; Candelario Bentham; Deiber Madrid; Nelvis Martinez;

Dairo Ríos; Edie Acosta; Hernando Franco; Rafael Herrera; Jose Mejía; Yamir Martinez; Genor Padilla; Irene Villamizar; Alvaro Pérez; Deiber Madrid; María Rodríguez; Nairobis Silva; Yoleidys Silva; Juvenal Herrera y Deibis Rojas

IED de Janeiro (Colombia)

kenyap1@gmail.com

Para citar este artículo

Pava, K., Acuña, A., Bentham, C., Madrid, D., Martinez, N., Ríos, D., Acosta, E., Franco, H., Herrera, R., Mejía, J., Martinez, Y., Padilla, G., Villamizar, I., Pérez, A., Madrid, D., Rodríguez, M., Silva, N., Silva, Y., Herrera, J. y Rojas, D. (2018). Textos Multimodales para el fortalecimiento de la Inteligencia Emocional. Cultura. Educación y Sociedad 9(2), 77-85. DOI: http://dx.doi.org/10.17981/cultedusoc.9.2.2018.07

\section{Resumen}

La inteligencia emocional es la capacidad del ser humano de controlar sus emociones, y de esta manera mejorar las relaciones interpersonales y son éstas las que juegan un papel fundamental en la vida del ser humano. La presente investigación tiene como objetivo general fortalecer la inteligencia emocional por medio de textos multimodales en la IED Janeiro en el departamento del Magdalena. El estudio se llevó a cabo desde la mirada cualitativa, empleando la entrevista estructurada como técnica de recolección de información. Los actores participantes fueron los estudiantes del grado noveno con la participación de (30) en la investigación. Como conclusiones se puede resaltar que los participantes se motivan a aprender y participan en el manejo y control de emociones presentes al momento de entrar en contacto con los procesos de enseñanza-aprendizaje.

Palabras clave: Inteligencia Emocional, Emociones, textos multimodales, Ova, TIC Educación

\begin{abstract}
Emotional intelligence is the ability of the human being to control their emotions, and in this way improve intra and interpersonal relationships and these are the ones that play a fundamental role in the life of the human being. The general objective of this research is to strengthen emotional intelligence through multimodal texts in IED Janeiro in the department of Magdalena. The study was carried out from the qualitative perspective, using the structured interview as a technique for gathering information. The participating actors were ninth grade students with the participation of (30) in the research. As conclusions, it can be highlighted that participants are motivated to learn and participate in the management and control of present emotions when they come into contact with the teaching-learning processes.
\end{abstract}

Keywords: Emotional intelligence, Emotions, multimodal texts, ICTs, Education

\footnotetext{
${ }^{1}$ Este artículo ha sido derivado del Programa de Fortalecimiento de la Cultura Ciudadana y Democrática CT+I a través de la IEP apoyada en TIC en el Departamento de Magdalena: CICLÓN. Desarrollado con docentes miembros del Grupo de investigación "Me Expreso" pertenecientes a la Institución Educativa Departamental de Janeiro.
}

${ }^{2}$ Líder de investigación del grupo "Me Expreso".

- The author; licensee Universidad de la Costa - CUC. 


\section{Introducción}

En la IED Janeiro desde hace ya varios años se han presentado varios incidentes de violencia entre alumnos, que se ha acrecentado con los días, entre estos se encuentran pleitos por situaciones sentimentales en adolescentes, por chismes y malos entendidos, y entre la población infantil las situaciones de intolerancia se dan por golpes entre niños incitados por los adolescentes y padres de familia, mal enfocados en " No dejar darse del otro", dejando a un lado cualquier respeto por objetos ajenos y situaciones especiales, discapacidad o género.

Según Guerrero (2016) en su mayoría estos problemas van relacionados a un contexto intrafamiliar basado en los regaños, golpes, palabras ofensivas, y abandono por parte de los padres, ya que la gran mayoría vive en familias disfuncionales y numerosas, por lo que los niños crecen sin recibir el afecto adecuado y presentan baja autoestima, causándole dificultad para expresar sus emociones y saber controlar. Esta situación se ve reflejada también en el mal ejemplo de los adultos, quienes se maltratan verbalmente delante de los jóvenes y niños sin importar si se van a golpes o no, y en algunos casos padres alcohólicos, fuera de estar inmerso en una sociedad muy machista, tendiente a la intolerancia y discriminación por género o tendencias sexuales.

Los alumnos de la IED Janeiro, son en su mayoría jóvenes que viven en hogares disfuncionales, de bajo recursos económicos y presentan muchos problemas de convivencia, originados principalmente por una baja autoestima y poca comunicación en sus hogares, propio de la cultura de esta zona, esto se ve reflejado en la incapacidad de estos niños y jóvenes de controlar las emociones, y la dificultad de expresar lo que sienten ante sus padres y terceros, creando dificultades tanto de autocontrol y convivencia, como también en el nivel de aprendizaje.

Las dificultades de los jóvenes y niños se ve reflejado en sus relaciones interpersonales, ya que ante la no facilidad de expresar sus pensamientos y emociones a los demás, se vuelven agresivos y deprimidos, creando dos contrastes: El joven extrovertido problemático y el joven introvertido y tímido, los cuales se desembocan en problemas sociales ante la comunidad, ya que son estigmatizados ante los miembros de esta y por los propios compañeros, siendo una causal de deserción escolar más grande, en los jóvenes varones, y en las niñas se presenta en la búsqueda temprana de afecto por parte de los jóvenes del sexo opuesto, propagándose en gran manera el embarazo adolescente.

Es por eso que este proyecto busca invertir sanamente el tiempo de los jóvenes bajo una nueva forma de canalizar emociones, aprender a sentirse pleno y augusto con uno mismo, y no depender de la aceptación de los demás y sobre todo, que los jóvenes expresen de manera integral, por medio del arte, música y literatura, lo que piensan de la vida, el mundo y como se sienten ante situaciones de la vida cotidiana que los afectan, y sobre todo como sacar al exterior todas estas frustraciones que conllevan a crear un ambiente hostil con todos sus compañero, es decir que el problema en sí, es la incapacidad que tienen algunos jóvenes de expresar abiertamente las emociones, porque no tienen costumbre el dialogo y la comunicación.

Los riesgos a nivel de convivencia dentro de la IED y en sus hogares son diversos y de allí se basa la importancia de este proyecto, ya que este abarca no solo la parte cognitiva del ser, sino también la física y espiritual, enlazado todas estas tres dimensiones en un ambiente socio cultural, teniendo una proyección significativa y con miras de alto impacto dentro de la comunidad. 


\section{Inteligencia emocional}

Inicialmente, se creía que la inteligencia dependía de la cantidad de conocimiento que un apersona tenía sobre algo y como memorizarla, sin embargo, notoriamente pudo verse que de nada servía el conocimiento si no se sabía aplicar a las esferas de la vida cotidiana, por lo que se dio más relevancia a IQ, y se fueron creando varias teorías con respecto al desarrollo de este, de allí tal vez podemos haber visto test para medir el CI (Coeficiente Intelectual) , pero, y a pesar de ello, habían algunas situaciones que enfrentaban personas con un IQ muy alto que no pudieron sostener debido a un agente interno: sus emociones.

Podríamos definir emociones como reacciones psicofisiológicas que representan modos de adaptación a ciertos estímulos del individuo cuando percibe un objeto, persona, lugar, suceso o recuerdo importante, lo que la real Academia define como Alteración del ánimo intensa y pasajera, agradable o penosa, que va acompañada de cierta conmoción somática, es decir, que las emociones forman parte de nuestra vida cotidiana y son resultados físicos a estímulos externos.

Entonces miramos lo que significa inteligencia, quien también definido por la real Academia la conceptualiza como la Facultad de la mente que permite aprender, entender, razonar, tomar decisiones y formarse una idea determinada de la realidad. Tomando estas dos premisas y al unirla podemos deducir que la inteligencia emocional es la capacidad del ser humano de dominar sus emociones, entenderlas, razonarlas y decidir de manera adecuada sin que esto lo afecte

Este enfoque de inteligencia emocional fue propuesto por Salovey y Meyer (1990) quienes hicieron un estudio físico de las emociones y las reacciones de los seres humanos ante ellas, sin embargo estas concepciones no tomaron importancia hasta que Goleman en su libro inteligencia emocional, mostrara una concepción más humana y aplicada sobre esta temática enfocado en la motivación y el marketing, situación que saco a la luz estos conceptos arrinconados por una década en el olvido

Según Goleman (1995) la I.E. abarca cinco competencias, teniendo como primera el conocimiento de las propias emociones, la segunda abarca la capacidad de controlar las emociones, la tercera competencia es la que promueve la capacidad de motivarse a uno mismo, la cuarta resalta el reconocimiento de las emociones ajenas y finalmente estas competencias nos llevan a tener el control de las relaciones, por otro lado Slovery y Meyer (1997) plantean que en algunas Instituciones Educativas, manejan también cuatro habilidades básicas tales como; la habilidad para percibir, habilidad para valorar y expresar emociones con exactitud, habilidad para acceder y/o generar sentimientos, que en última instancia son las que facilitan la generación de pensamiento frente a las emociones ; también está la habilidad, que permite la comprensión para regular las emociones y avanzar en el conocimiento de las habilidades intelectuales.

Basados en estos dos aportes, e integrándolo al ámbito educativo, es importante mencionar entonces el estudio realizado por Berrocal y Extremera (2007), quienes se han dedicado a realizar varias investigaciones utilizando la IE en su manera integradora a la sociedad y la educación, enfocados en la premisa de que una adecuada inteligencia emocional mejora grandemente el desarrollo cognitivo del ser humano, ellos afirman en sus estudios que si el niño o adolescente es capaz de desarrollar una inteligencia emocional, eso implicaría mejoramiento de sus relaciones hacia los demás y también un aumento en su capacidad cognitiva. 
Finalmente, con relación al tema de la inteligencia emocional, (Fernandez \& Extremera, 2015) se deduce que, si existe motivación en el estudiante, y posee una capacidad de controlar sus emociones esto traería un aumento del rendimiento académico y su comportamiento, siendo este el objetivo del proyecto.

\section{Las TIC}

Las Tecnologías de la Información y las Comunicación (TIC), se referencian como el conjunto de las tecnologías, que acceden a la adquisición, producción, almacenamiento, tratamiento, comunicación, registro y presentación de informaciones, en forma de voz, imágenes y datos contenidos en señales de naturaleza acústica, óptica o electromagnética, para fortalecer la educación en mejorar su práctica de aula, como herramientas facilitadora en el proceso de transformación (Sánchez, 2013).

El MEN propone por medio de su página que se tomen las TIC como una poderosa herramienta pedagógica y didáctica que aproveche nuestra capacidad multisensorial. Es decir que la combinación de textos multimedia permite que el conocimiento se muestre más vívido y dinámico, lo cual resulta crucial para el aprendizaje. Lo que haría un cambio radical en el joven, En la actualidad estamos en la era de la información, y es muy importante destacar que la generación que se está levantando, ha desarrollado habilidades sensoriales más fuertes que las generaciones anteriores, ya que el auge de información virtual ha permitido unir el mundo al alcance un clic, y este a su vez viene con textos no solo escrito, sino con un entorno visual, grafico, con audio y video, que permiten a los sentidos sentirse parte del suceso y además mantiene concentrado al sujeto más tiempo que cualquier otro medio convencional.
Si tomamos esta valoración sobre los programas multimedias y las TIC's se puede afirmar que estas forman parte integral de la Educación Moderna, por eso es casi imposible en la actualidad realizar algún tipo de propuesta pedagógica sin el apoyo de las TIC`s, y es que estamos en la era digital, como lo expresa Sánchez, (2013). se hace necesario apoderarse de las TIC, y estrecharlo adecuadamente con la Educación.

Teniendo también un alcance significativo del aprendizaje, este a su vez y las acciones sensoriales se apoyan en el proceso meta-cognitivo del niño y adolescente produciendo a su vez pensamiento crítico y razonamiento, basado ya no en una idea sin figura, sino también el haber pasado por sus sentidos la imagen, sonido, figura de algo que no se conocía. Es en este medio como la IEP, permite que los estudiantes y jóvenes, aprovechen estas nuevas tecnologías para el aprendizaje significativo y promuevan la curiosidad basada en la indagación, siendo de esta manera inducidos a un proceso investigativo produciendo así el conocimiento propio. (Ciro, 2012).

\section{Textos Multimodales}

Finalmente podemos agregar que los textos multimodales son aquellos cuando se combina dos o más sistemas semióticos. Orjuela, (2010). Afirman que hay cinco sistemas semióticos en total: primeramente, el Lingüísticos que comprende todo lo relacionado con el vocabulario y su estructura, el segundo es el Visual, este corresponde a todo lo que podamos apreciar por la vista (colores, puntos de vista, imagen) el tercero es el. Audio cuyos aspectos se basan en el sentido auditivo tales como el volumen, el tono y el ritmo de la música y efectos de sonido. El cuarto componente es el gestual, que comprende aspectos del lenguaje corporal en sí, como gestos y acciones. Finalmente, como quinto aspecto 
se muestra el espacial, el cual rige las situaciones de ubicación de objetos en el espacio, tanto de la persona como de los objetos próximos a ella.

Por lo tanto, los textos multimodales abarcan todas las acciones que hacemos diariamente para comunicarnos, de allí la facilidad para implementar en el proyecto, porque da la oportunidad a los alumnos de decidir de qué manera se va a expresar de manera libre y sin temor a no ser valorados. (Garzón y Acuña. 2016). Esta forma de presentarse implica que la literatura no solo abarca textos escritos como tal, sino todo tipo de expresión que permita la comunicación entre dos personas, sin importar la forma ni el estilo, ya que esta no es más que un simple código fonético, o grafico como son las letras, sin embargo, la comunicación sobrepasa ese código y permite mostrar el mensaje que se quiere transmitir según la forma en que el emisor lo desee. (Salcedo, 2009).

\section{Metodología}

El Alcance de la investigación es Descriptiva, por lo que permite estudiar las características, de la población objeto de estudio, a tal punto que hace estudio minucioso de las categorías, señalando, formas de conducta y actitudes del universo investigado, estableciendo los comportamientos concretos, para ir a descubrir la relación que tienen las categorías con lo investigado. El investigador se apoya en la observación permanente, para revelar otras situaciones que permean al objeto investigado (Martínez, 2006).

La siguiente investigación es de tipo cualitativa, bajo un diseño transeccional, esto debido a la naturaleza de la investigación, la cual es de carácter descriptiva y de un nivel no experimental, por lo que es obligatoria y necesaria conocer más de fondo al objeto de estudio, y presentar un análisis interdisciplinar que permita lograr el propósito planteado y obtener resultados más a fondo de los pensamientos y situaciones que están generando el problema, y cómo reaccionan estos frente a la implementación de la propuesta.

\section{Escenarios y actores}

La población en estudio, fueron los alumnos del grado noveno de la IED Janeiro sede principal, con un total son 13 estudiantes, una muestra de los grados en los que se ha identificado como transicionales, siendo esta la población más afectada por problemas de abandono en sus hogares, maltrato psicológico o negligencia emocional total o parcial por parte de los padres, lo que conduce mal trato, baja autoestima, rendimiento académico pobre. Esta población en su mayoría viene de hogares disfuncionales y donde la comunicación está basada en simples órdenes y gritos hacia los menores, y poca atención.

\section{Recolección y Procedimiento de Información}

La información de la investigación se va a realizar por medio del método de observación participante, utilizando talleres y relatorías individuales (orales o escritas), finalmente se hará un diario de relatorías generales donde se registrará los comportamientos y situaciones que se van presentando a medida que se desarrolla la implementación del proyecto. Cada docente realizara unos Estos talleres llevaran preguntas indirectas sobre algunas situaciones llevando al estudiante a mostrar que es lo que lo está afectando en su vida cotidiana y le permita expresarse libremente, siendo este el objetivo primario de la investigación, ya que por otros medios sería difícil obtener información precisa debido a los problemas de comunicación que presentan los jóvenes en estudio. 
Cada docente en su área aplicara un taller ajustado según el grado y la capacidad del estudiante, de allí el docente encargado del grupo realizara un análisis de las respuestas y presentaran una síntesis de los resultados mediante un informe escrito.

Agregado a este taller, se realizarán varias entrevistas directas con los jóvenes que muestran mayor necesidad en relación con el control de emociones, y de igual manera con los niños que se negaron a traba- jar de manera escrita o figurativa. Todas estas acciones re realizaran teniendo en cuenta la Sistematización como proceso investigativo.

\section{Resultados}

A continuación, se presentan lo hallazgos derivados de los instrumentos aplicados, (entrevista estructurada). Y diario de campo.

\begin{tabular}{|c|c|c|c|}
\hline $\begin{array}{l}\text { Categoría de } \\
\text { estudio }\end{array}$ & $\begin{array}{c}\text { Pregunta } \\
\text { orientadora }\end{array}$ & $\begin{array}{l}\text { Discurso de } \\
\text { los actores }\end{array}$ & $\begin{array}{c}\text { Articulación y } \\
\text { sistematización teórica }\end{array}$ \\
\hline $\begin{array}{l}\text { Textos } \\
\text { Multimodales }\end{array}$ & $\begin{array}{l}\text { ¿Te gustaría } \\
\text { expresar tus } \\
\text { emociones } \\
\text { de manera } \\
\text { virtual } \\
\text { ya sea } \\
\text { cantando, } \\
\text { dibujando, } \\
\text { escribiendo o } \\
\text { simplemente } \\
\text { narrando } \\
\text { ¿Por qué? }\end{array}$ & $\begin{array}{l}\text { "Escribiendo porque expreso } \\
\text { emociones, que simplemente no me } \\
\text { atrevo en ocasiones a expresar lo } \\
\text { que siento diciéndolo, y mejor lo } \\
\text { escribo. Me siento la mayoría de veces } \\
\text { mejor expresando mis emociones } \\
\text { escribiendo, expreso mi estado de } \\
\text { ánimo y ciertas actitudes que muchas } \\
\text { veces le incomoda a los demás, } \\
\text { aunque somos libres de expresar } \\
\text { nuestros sentimientos o emociones", } \\
\text { "escribiendo porque así a una persona } \\
\text { no le da pena expresar lo que piensa } \\
\text { lo que siente y se da hacer valiente } \\
\text { por medio de escritos porque a veces } \\
\text { hay muchas personas que se burlan } \\
\text { por la forma como hablamos o como } \\
\text { nos expresamos sin saber que le está } \\
\text { haciendo daño a una persona que por } \\
\text { medio de su escrito es una persona } \\
\text { muy valiente se da a conocer en la } \\
\text { profesión de escritor", "no, a que las } \\
\text { emociones son personales al menos } \\
\text { que la publique, pero mejor es no hacer } \\
\text { nada y calmarse sin argumentar } \\
\text { nada. Pero sería bueno expresar a una } \\
\text { persona lo que sentimos en qué estado } \\
\text { estamos" a mí me gusta expresar } \\
\text { mis emociones escribiendo porque me } \\
\text { entretengo y así poder aprender más } \\
\text { mis estudios y poder seguir adelante } \\
\text { me gusta ayudarle a mis amigas } \\
\text { escribiendo en sus cuadernos cuando } \\
\text { no vienen a clases cuando hacemos } \\
\text { trabajos en grupos también me gusta } \\
\text { cantar y dibujar en el colegio". }\end{array}$ & $\begin{array}{l}\text { Esta primera pregunta se puede } \\
\text { observar que la mayoría de } \\
\text { los estudiantes manifiesta el } \\
\text { poder expresar sus emociones } \\
\text { de manera libre, y de diferentes } \\
\text { maneras, reconociéndolo como } \\
\text { un proceso natural de sus seres, } \\
\text { de su yo interno, lo que arroja } \\
\text { que de alguna manera vaya } \\
\text { acompañada de cierta conmoción } \\
\text { somática. } \\
\text { De esta manera se toman } \\
\text { respuestas muy relevantes } \\
\text { como la siguiente: "sí, porque } \\
\text { a mí me gusta expresarme de } \\
\text { todas las maneras posibles } \\
\text { para que puedan entender lo } \\
\text { que esto diciendo y expresando } \\
\text { para las demás personas que } \\
\text { están a mi alrededor. para que } \\
\text { puedan comprender también } \\
\text { como se expresan los demás y } \\
\text { comprenderlas", y nos situamos } \\
\text { en lo dicho por el autor (Lantieri } \\
\text { \& Goleman, 2009) "la I.E. abarca } \\
\text { cinco competencias, teniendo } \\
\text { como primera el conocimiento } \\
\text { de las propias emociones, la } \\
\text { segunda abarca la capacidad } \\
\text { de controlar las emociones, } \\
\text { la tercera competencia es la } \\
\text { que promueve la capacidad de } \\
\text { motivarse a uno mismo, la cuarta } \\
\text { resalta el reconocimiento de las } \\
\text { emociones ajenas y finalmente } \\
\text { estas competencias nos llevan a } \\
\text { tener el control de las relaciones" }\end{array}$ \\
\hline
\end{tabular}




\begin{tabular}{|c|c|c|c|}
\hline $\begin{array}{l}\text { Inteligencia } \\
\text { emocional }\end{array}$ & $\begin{array}{l}\text { ¿Sabes } \\
\text { que es la } \\
\text { inteligencia } \\
\text { emocional } \\
\text { y para que } \\
\text { puede servir } \\
\text { durante } \\
\text { tu etapa } \\
\text { escolar? }\end{array}$ & $\begin{array}{l}\text { "yo tendría una inteligencia emocional } \\
\text { para siempre estar alegre, cuando } \\
\text { somos personas alegres para siempre } \\
\text { sonreírle a la vida y para ser una } \\
\text { buena alumna para la institución } \\
\text { y para la familia", "la inteligencia } \\
\text { emocional nos puede servir mucho } \\
\text { durante nuestra etapa escolar que es } \\
\text { algo muy importante para nosotros } \\
\text { nos puede servir más adelante en } \\
\text { nuestra vida cotidiana", "puede } \\
\text { servir en muchas cosas depende a } \\
\text { las noticias que nos den a veces a las } \\
\text { misma emociones nos pueden ayudar } \\
\text { a ponernos las pilas en lo que se va a } \\
\text { hacer", "es deber controlar nuestras } \\
\text { emociones y tratar de que alguna } \\
\text { emoción no nos afecte de manera de } \\
\text { que nos baje el rendimiento académico } \\
\text { si sabes controlarlas nos van a hacer } \\
\text { de mucha ayuda porque sabremos } \\
\text { tomar las decisiones correctas que en } \\
\text { futuro nos serán de mucha ayuda"; } \\
\text { "la inteligencia emocional tanto la } \\
\text { de nosotras puede ser muy útil ya } \\
\text { que si sabemos entender conocer los } \\
\text { sentimientos de los demás". }\end{array}$ & $\begin{array}{l}\text { Teniendo en cuenta lo que piensa } \\
\text { cada estudiante, respecto a lo } \\
\text { que es la inteligencia emocional, } \\
\text { y de qué manera puede ayudar en } \\
\text { su etapa escolar a nivel general } \\
\text { se cita que: "había algunas } \\
\text { situaciones que enfrentaban } \\
\text { personas con un IQ muy alto que } \\
\text { no pudieron sostener debido a un } \\
\text { agente interno: sus emociones." } \\
\text { Es claro que los estudios arrojan } \\
\text { que la inteligencia emocional de } \\
\text { alguna u otra forma contribuye } \\
\text { a tus procesos de aprendizaje } \\
\text { como se cita en esta respuesta } \\
\text { "yo tendría una inteligencia } \\
\text { emocional para siempre estar } \\
\text { alegre, cuando somos personas } \\
\text { alegres para siempre sonreírle } \\
\text { a la vida y para ser una buena } \\
\text { alumna para la institución y } \\
\text { para la familia". teniendo en } \\
\text { cuenta lo anterior se infiere que } \\
\text { desarrollar la I.E permitirá } \\
\text { ser mejor a nivel académico y } \\
\text { escolar, y en la familia, con el } \\
\text { fin de tener aceptación en estas } \\
\text { dos facetas como lo expresa } \\
\text { (Fernandez \& Extremera, } 2015 \text { ). }\end{array}$ \\
\hline $\begin{array}{l}\text { Inteligencia } \\
\text { emocional }\end{array}$ & $\begin{array}{l}\text { ¿Creerías } \\
\text { que } \\
\text { controlando } \\
\text { esa emoción } \\
\text { que siempre } \\
\text { te domina } \\
\text { podrías } \\
\text { tener mejor } \\
\text { desempeño } \\
\text { académico? } \\
\text { ¿por qué? }\end{array}$ & $\begin{array}{l}\text { "Podría ser porque siempre que estoy } \\
\text { triste trato como de cambiar mi } \\
\text { estado de ánimo también cuando estoy } \\
\text { en momentos de ira, analizo y me } \\
\text { tranquilizo. Aunque yo siempre trato } \\
\text { de llevarme bien con las demás pero no } \\
\text { siempre las personas te van a aceptar, } \\
\text { me sirve de mucha ayuda porque tomo } \\
\text { las decisiones que sean agradables } \\
\text { para mí y los demás", "si porque a } \\
\text { veces nosotros no sabemos controlar } \\
\text { nuestras emociones y no podemos } \\
\text { dar lo mejor de nosotros", "si ya que } \\
\text { si la emoción que estoy sintiendo es } \\
\text { enojo, tristeza, controlándolo podría } \\
\text { concentrar más en cada una de las } \\
\text { clases dictadas por el maestro", "para } \\
\text { mi si porque a pesar de mis emociones } \\
\text { durante clases les prestó atención a } \\
\text { mis docentes y así puedo tener buen } \\
\text { desempeño académico poder tener un } \\
\text { buen futuro y prestando atención a } \\
\text { clases puedo ser una buena alumna y } \\
\text { sin tener problemas en el desempeño } \\
\text { académico". }\end{array}$ & $\begin{array}{l}\text { Una adecuada inteligencia } \\
\text { emocional mejora grandemente } \\
\text { el desarrollo cognitivo del ser } \\
\text { humano, lo que indica que } \\
\text { incluye de manera significativa } \\
\text { el hecho que los estudiantes de } \\
\text { la IED Janeiro puedan expresar } \\
\text { sus sentimientos de manera } \\
\text { abierta, y puedan motivarme } \\
\text { a aprender a pesar de las } \\
\text { dificultades oo las situaciones un } \\
\text { poco complejas, pues, el estado } \\
\text { de ánimo influye directamente } \\
\text { en el rendimiento académico y } \\
\text { que controlar sus emociones le es } \\
\text { de mucha ayuda en la toma de } \\
\text { decisiones. (Fernández-Martínez } \\
\text { \& Montero-García, 2016). }\end{array}$ \\
\hline
\end{tabular}

Fuente: Elaboración propia. (2018). 


\section{Conclusiones}

Los estudiantes como los docentes de la IED janeiro, reconocen que, mediante el objeto virtual de aprendizaje, a través de las formas multimodales, muchas expresadas de manera escrita, oral, dibujada, entre otras. Con el fin de canalizar esa energía empleada en cada una de sus emociones. Por otro lado, el articular las formas multimodales con el uso de las TIC, les parece novedoso ya que son nativos de la nueva era digital, lo que despierta en si el interés y la motivación de querer plasmar como se sienten, de manera sistematizada, permite que la investigación sea más acertada y haya toda la posibilidad de su implementación, mantenimiento y conservación en la línea del tiempo.

La observación directa de estudiantes que de alguna u otra manera manifestaban conductas muy marcadas de las diferentes emociones, tristes, alegría, rabia, cohibido, entre otras; permitió ver que tan efectivo podía ser instruirles acerca de los textos multimodales, teniendo en cuenta sus fuertes en cada talento innato que posean, esto les permitió sentirse identificados, libres a las formas de expresión, lo que felicito el trabajo de campo, sabiendo que piensa cada niño con cada emoción evidenciada.

Finalmente con relación al tema de la inteligencia emocional, se deduce que si existe motivación en el estudiante, y posee una capacidad de controlar sus emociones lo que permite aumento del rendimiento académico y su comportamiento, siendo este el objetivo del proyecto.

\section{Referencias}

Avendaño, I., Cortés, O., Guerrero, H. (2015) Competencias sociales y tecnologías de la información y la comunicación como factores asociados al desempeño en estudiantes de básica primaria con experiencia de desplazamiento forzado Diversitas: Perspectivas en Psicología, vol. 11, núm. 1, 2015, pp. 13-36 Universidad Santo Tomás Bogotá, Colombia.http://www.scielo.org.co/pdf/dpp/ v11n1/v11n1a02.pdf

Bizquerra, R., Pérez, J. C., \& García, E. (2015). Inteligencia emocional en educación. Revista Complutense de Educación, 27(2), 339. Obtenido de https://revistas.ucm.es/ index.php/RCED/article/viewFile/52196/48126.

Ciro, C. (2012). Aprendizaje Basado en Proyectos (A.B.Pr) Como estrategia de enseñanza y Aprendizaje en la Educación Básica y Media. Universidad nacional de Colombia. Recuperado de: www.bdigital.unal.edu. co/9212/1/43253404.2013.pdf .

Fernandez, P., \& Extremera, N. (2015). Inteligencia Emocional y Educacion. Revista Electrónica de Investigación Educativa, 6. Obtenido de http:// www.redalyc.org/pdf/155/15506205. pdf.

Fernández-Martínez, A. M., \& MonteroGarcía, I. (2016). Aportes para la educación de la Inteligencia Emocional desde la Educación Infantil. Revista Latinoamericana de Ciencias Sociales, Niñez y Juventud, 14(1), 53-66. Obtenido de http://www.scielo.org.co/pdf/rlcs/v14n1/v14n1a03. pdf. 
Garzón, E. y Acuña, L. (2016). Integración de los proyectos transversales al currículo: una propuesta para enseñar ciudadanía en ciclo inicial. Revista Electrónica "Actualidades Investigativas en Educación", Vol. 16 p. 1-26. Recuperado de http://imss.redalyc. org/articulo.oa?id=44746861010.

Guerrero, H. y Cepeda, M. (2016) Uso de estrategias pedagógicas para el fortalecimiento de la convivencia escolar de jóvenes vulnerables.http:// saber.ucv.ve/ojs/index.php/rev_ped/ article/view/12501.

Lantieri, L., \& Goleman, D. (2009). Inteligencia Emocional Infantil (III ed.). Barcelona, España: Aguilar. Obtenido de https://www.murciaeduca.es/ cpjaracarrillo/sitio/upload/Inteligencia_Emocional_Infantil_y_Juvenil._ Daniel_Goleman.pdf.

Martínez, M. (2006). La investigación cualitativa (Vol. 9). (R. d. psicología, Ed.) Lima, Perú. Obtenido. de http:// revistasinvestigacion.unmsm.edu.pe/ index.php/psico/article/view/4033
MinEducación. (Abri/Mayo de 2004). Al tablero. Obtenido de Una llave maestra Las TIC en el aula: https:// www.mineducacion.gov.co/1621/article-87408.html.

Orjuela, D. (2010). Acercamiento a la integración curricular de las tic. Praxis \& Saber. Vol. 1, p. 111-136. Recuperado de http://www.redalyc.org/articulo. oa?id=477248386007

Salcedo, J. (2009). La investigación Acción en la transformación e integración curricular. Un diálogo crítico desde la IED Delia Zapata Olivella. Revista actualidad pedagógica $\mathrm{N}^{\circ}$ 54/Julio - Dic. 2009. Recuperado de: https://revistas.lasalle.edu.co/index. php/ap/article/download/961/868.

Sánchez, H. (2013). La actividad científico - investigativa en educación. Revista Científico-Metodológica, No. 57, pp.21-25, julio-diciembre. Recuperado de: http/:www.redalyc.org/articulo. oa?id=360634164005 . 